26. Olin $\mathrm{P}$, Hallander HO. Marked decline in pertussis followed reintroduction of pertussis vaccination in Sweden. Euro Surveill 1999;4(12):128-129.

27. Swedish Institute for Infectious Disease Control. Pertussis surveillance in Sweden with enhanced

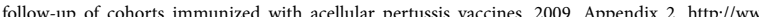
follow-up of cohorts inmunized wh acellular pertussis vaccines. 200. Appendix 2. http://www. smittskyddsinstitutet.se/upload/Pablikationer/11-y-report-app202-GSK.pd (accessed 15 December

28. Gustafsson L, Hessel L, Storsaeter J, Olin P. Long-term follow-up of Swedish children vaccinated with acellular pertussis vaccines at 3,5 , and 12 months of age indicates the need for a booster dose at 5 to 7 years of age. Pediatrics 2006;118(3):978-98

9. Pavlov DN, Van Zyl WB, Van Heerden J, et al. Prevalence of vaccine-derived polioviruses in stools of immunodeficient children in South Africa. J Appl Microbiol 2006;101(6):1367-1379.

0. Global Polio Eradication Initiative - Strategic Plan 2009 - 2013. http://www.polioeradication.org/ content/publications/PolioStrategicPlan09-13_Framework.pdf (accessed 19 October 2010).

1. von Gottberg A, de Gouveia L, Madhi SA, et al. Impact of conjugate Haemophilus influenzae type b (Hib) vaccine introduction in South Africa. Bull World Health Organ 2006;84(10):811-818

32. Gold R, Scheifele D, Barreto L, et al. Safety and immunogenicity of Haemophilus influenzae vaccine (tetanus toxoid conjugate) administered concurrently or combined with diphtheria and tetanus toxoids, pertussis vaccine and inactivated poliomyelitis vaccine to healthy infants at two, four and six months of ge. Pediatr Infect Dis J 1994:13(5):348-355.

33. Lagos $\mathrm{R}$. Horwitz $\mathrm{L}$ Toro $\mathrm{I}$ et al. Large scale, postlicensure, selective vaccination of Chilean infants with PRP-T conjugate vaccine: practicality and effectiveness in preventing invasive Haemophilus influenzae type b infections. Pediatr Infect Dis J 1996;15(3):216-222.

34. Tsebe KV, Burnett RJ, Hlungwani NP, Sibara MM, Venter PA, Mphahlele MJ. The first five years of universal hepatitis B vaccination in South Africa: evidence for elimination of HBsAg carriage in under 5-year-olds. Vaccine 2001;19(28-29):3919-3926.

35. Clark A, Sanderson C. Timing of children's vaccinations in 45 low-income and middle-income countries: an analysis of survey data. Lancet 2009;373(9674):1543-1549.

36. Guerra FA. Delays in immunization have potentially serious health consequences. Paediatr Drugs 2007;9(3):143-148.

\title{
Assessing menopausal status in women aged 40 - 49 using depot-medroxyprogesterone acetate, norethisterone enanthate or combined oral contraception
}

Mags E Beksinska, Jenni A Smit, Immo Kleinschmidt, Tim M M Farley

Background. Determining symptoms of menopause in older users of hormonal injectable contraceptives may be challenging, owing to method-induced amenorrhoea, suppression of follicle-stimulating hormone (FSH) and vasomotor symptoms.

Objective. To investigate menopausal symptoms in women aged 40 - 49 using injectable contraceptives depot-medroxyprogesterone acetate (DMPA), norethisterone enanthate (NET-EN) or combined oral contraceptives (COCs), compared with non-users of hormonal contraception.

Methods. Women using DMPA ( $N=127)$, NET-EN $(N=102)$, COCs $(N=106)$ and 161 non-hormonal contraceptive user controls were recruited. Baseline visit serum FSH was measured and information was collected on vasomotor symptoms and menstrual regularity.

Results. There was no difference in reporting of vasomotor symptoms between the groups. There was no evidence of a difference in FSH level between non-users (mean FSH $26.7 \mathrm{IU} / \mathrm{ml}$, SD 28.7) and DMPA users (mean FSH $23.1 \mathrm{IU} / \mathrm{ml}$, SD 27.8) $(p=0.64)$. However, the NET-EN (mean FSH $11.0 \mathrm{IU} / \mathrm{ml}$, SD 10.9) $(p=0.003)$ and COC groups (mean FSH $12.5 \mathrm{IU} / \mathrm{ml}$, SD 18.7) ( $p=0.001)$ had significantly lower FSH levels compared with the non-user group.

Conclusion. The lower FSH levels found in the NET-EN and $\mathrm{COC}$ users compared with controls may indicate a greater degree of suppression of FSH levels in these two methods, compared with DMPA. Measuring FSH levels may therefore be informative of menopausal status in DMPA users but not in NET-EN or COC users. Vasomotor symptoms may assist in assessing menopausal status in DMPA, NET-EN and COC users.

S Afr Med J 2011;101:131-135
Determining the onset of menopause in older users of hormonal injectable contraceptives depot medroxyprogesterone acetate (DMPA) and norethisterone enanthate (NET-EN) can be challenging.

Maternal, Adolescent and Child Health, Department of Obstetrics and Gynaecology, University of the Witwatersrand, Overport, Durban

Mags E Beksinska, $\mathrm{PhD}$

Jenni A Smit, $\mathrm{PhD}$

London School of Hygiene and Tropical Medicine, London, UK Immo Kleinschmidt, $\mathrm{PhD}$

UNDP/UNFPA/WHO/World Bank Special Programme of Research, Development and Research Training in Human Reproduction, Department of Reproductive Health and Research, World Health Organization, Geneva, Switzerland Tim M M Farley, PhD

Corresponding author: $M$ Beksinska (mbeksinska@match.org.za)
These contraceptive methods may mask menopausal symptoms such as amenorrhoea, which is a common side-effect of the method itself and increases in incidence over length of time used. ${ }^{1}$ DMPA has been shown to relieve vasomotor symptoms in perimenopausal women. ${ }^{2,3}$ Furthermore, DMPA and NET-EN are known to suppress the midcycle surge of follicle-stimulating hormone (FSH) and luteinising hormone (LH), thereby reducing raised FSH levels, although the tonic release of these gonadotrophins continues at luteal phase levels. ${ }^{4}$ Detection of menopause or perimenopause may, therefore, present difficulties in this group of contraceptive users. In older combined oral contraceptive (COC) users, it is recommended that FSH is measured on the seventh day of the pill-free interval. ${ }^{5}$ However, appropriate advice for DMPA and NET-EN users is less clear, and it has been suggested that the options are to continue using the method until the woman reaches 55 years or to change to a non-hormonal method of contraception. ${ }^{6}$ 
In South Africa, $63.1 \%$ of women aged 40 - 44 and $57.2 \%$ aged 45 49 use contraception. ${ }^{7}$ Of these women approximately one-third use injectable contraceptives DMPA or NET-EN. Less women (10\%) use COCs. ${ }^{7}$ While our primary aim was to study bone density in older women using hormonal contraceptives, a secondary objective was to investigate the menopausal status in participants who used hormonal contraception. This article presents the baseline results of the latter component of the study.

\section{Subjects and methods}

A cohort of women aged 40 - 49 were recruited from a large family planning clinic in Durban. Eligible participants had used a hormonal method of contraception for at least 1 year (hormonal user group) or had not used a hormonal method for at least 5 years (non-user group), had not lactated or delivered in the past 6 months, had never used medication known to affect calcium metabolism for more than 3 months, and did not have a chronic disease affecting calcium metabolism. Women who had amenorrhoea for at least 1 year were excluded.

On recruitment, a questionnaire was administered to elicit information on lifetime contraceptive history, fertility history, menopausal symptoms (hot flushes, night sweats, skin changes and dry vagina in last 3 months) and menstrual cycle regularity. Questions were also asked on smoking, diet, exercise and caffeine and alcohol intake.

\section{Hormones and assays}

A blood sample was drawn on the day of recruitment regardless of timing of the menstrual cycle or injection/COC dosage interval. Many women were experiencing irregular menstrual cycles owing to the use of injectable hormonal contraception or perimenopause. Consequently, a blood draw in the early follicular phase of the menstrual cycle was not specified.

Serum FSH levels were determined by immunoassay on the Roche Modular Analytics E170 (Elecsys module) immunoassay analyser. A FSH level $\geq 25.8$ milli-international units per millilitre $(\mathrm{mIU} / \mathrm{ml})$ was considered to be in the menopausal range (King Edward VIII Hospital, Durban; Chemical Pathology Laboratory criteria using Roche Elecsys FSH expected values)

\section{Assay specificity}

Regarding analytical specificity, the following cross-reactions with other hormones have been determined for the monoclonal antibody used: luteinising hormone, thyroid-stimulating hormone, human chorionic gonadotropin, human growth hormone and human placental lactogen at $<0.1 \%$.

\section{Assay sensitivity}

The lower detection limit is $<0.10 \mathrm{mIU} / \mathrm{ml}$. The maximum of the measuring range is $200 \mathrm{mIU} / \mathrm{ml}$. Values above this figure are reported as $>200 \mathrm{mIU} / \mathrm{ml}$.

\section{Test precision (reproducibility)}

The within-assay coefficients of variation ranged between $0.78 \%$ and $1.5 \%$ for quality control samples with mean values of 9.53 and $33 \mathrm{mIU} /$ $\mathrm{ml}$. Studies have shown that DMPA and NET-EN suppresses raised FSH and LH levels in perimenopausal and postmenopausal women in the early phase of the injection cycle; however, the suppressed levels almost always remained in the menopausal range. ${ }^{8,9}$

To investigate whether DMPA and NET-EN interfered with the FSH assay, control test samples and patient samples with high and low values of FSH were spiked with both contraceptives at levels above the highest circulating levels of MPA and NET described in the literature. ${ }^{10}$ Only very small differences were observed, which fell into the quoted within-run precision of the test.

\section{Measurements}

The examination included height, weight, blood pressure and waist and hip measurements using a standard protocol. Body mass index (BMI) was calculated from the weight and height as $\mathrm{kg} / \mathrm{m}^{2}$. Participants were followed-up at 6-monthly intervals for a total of 5 years. Our findings are based on the baseline data collected at recruitment and are cross-sectional in nature.

The characteristics of women in the study were quantified as means $( \pm \mathrm{SD})$, or percentages. Differences in characteristics between the contraceptive groups were assessed using one-way analysis of variance. FSH levels were in addition classified into 2 categories according to laboratory cut-off levels for premenopausal $(<25.8 \mathrm{mIU} / \mathrm{ml})$ and perimenopausal/menopausal ( $\geq 25.8 \mathrm{mIU} / \mathrm{ml}$ ). The effect of DMPA and NET-EN on the menstrual cycle meant that perimenopause could not be indicated by amenorrhoea in these hormonal contraceptive users. We therefore classified menopausal status using FSH and vasomotor symptoms. Women with an FSH outside the normal range and with at least one vasomotor symptom reported in the last 3 months were classified as perimenopausal. The association between vasomotor symptoms and contraceptive method user group was assessed using chi-square analysis and adjusted for age using logistic regression analysis. The association between FSH level and user group, adjusted for age, was estimated by using multiple variable linear regression. The study was powered to detect differences in bone mass between users and non-users of hormonal contraceptives; detailed methodology for this study is described elsewhere. ${ }^{11}$

Data were analysed using the statistical package STATA (V.10 College Station, TX, USA). Recruitment commenced in 2000 and was completed in 2003. The study was completed in 2007 . Women were informed about the study and, if they were interested in volunteering to participate, they were asked to give written informed consent. Ethical approval was granted by the University of the Witwatersrand, Human Subjects Research Committee (Protocol Number M981001), and by the Scientific and Ethical Review Group of the World Health Organization.

\section{Results \\ Socio-demographic and lifestyle characteristics of subjects}

A total of 496 women were recruited. There were some differences between the characteristics of the 4 groups in the 40 - 49-year age group (Table I). Most women presenting as non-users tended to be $>45$ years, resulting in this group being on average 2 years older than the 3 user groups $(p<0.001)$. There were a similar proportion of African women in both the injectable and non-user groups, but there was a significant difference in the composition of the COC group, where $26 \%$ were Indian women. Across all groups, few women exercised, and none in the 2 injectable groups reported following a diet in the last 6 months. Less than a fifth of the women had ever smoked, and few were current smokers.

\section{Reproductive characteristics}

Reproductive characteristics are shown in Table II. Age of menarche was around 15 years, and parity was between 3 and 4 . The majority of women had used their group method for over 3 years at recruitment, and most were long-term users of the study methods.

\section{Menopausal status}

All FSH samples analysed for this study were above the lower detection limit, and no sample $>200 \mathrm{mIU} / \mathrm{ml}$ was reported. FSH level 
Table I. Socio-demographic and lifestyle characteristics of subjects in the 40 - 49 -year age range by contraceptive method use

\begin{tabular}{|c|c|c|c|c|c|}
\hline Characteristics & DMPA $(N=127)$ & NET-EN $(N=102)$ & $\operatorname{COC}(N=106)$ & $\begin{array}{l}\text { Non-user controls } \\
(N=161)\end{array}$ & $p$ value \\
\hline Mean age, years (SD) & $43.6(2.7)$ & $43.0(2.2)$ & $43.6(2.6)$ & $45.4(2.5)$ & $<0.0001$ \\
\hline $\begin{array}{l}\text { Mean highest } \\
\text { education grade (SD) }\end{array}$ & $8.5(3.3)$ & $9.8(3.1)$ & $9.8(2.4)$ & $9.1(2.7)$ & 0.012 \\
\hline \multicolumn{6}{|l|}{ Marital status (\%) } \\
\hline Married/cohabiting & 46.1 & 52.1 & 57.1 & 41.0 & \multirow[t]{4}{*}{$<0.0001$} \\
\hline $\begin{array}{l}\text { Regular partner - } \\
\text { not cohabiting }\end{array}$ & 3.2 & 7.7 & 5.7 & 3.7 & \\
\hline Casual partner & 38.9 & 36.5 & 28.6 & 25.5 & \\
\hline No partner & 11.9 & 2.9 & 7.6 & 29.8 & \\
\hline \multicolumn{6}{|l|}{ Employment status \% } \\
\hline $\begin{array}{l}\text { Employed full/ } \\
\text { part-time }\end{array}$ & 44.5 & 73.5 & 71.5 & 63.4 & \multirow[t]{3}{*}{$<0.0001$} \\
\hline Unemployed & 54 & 19.6 & 23.8 & 33.5 & \\
\hline Housewife & 1.6 & 6.9 & 4.8 & 3.1 & \\
\hline \multicolumn{6}{|l|}{ Ethnicity \% } \\
\hline Black & 98.4 & 95.2 & 67.0 & 94.4 & \multirow[t]{3}{*}{$<0.0001$} \\
\hline Coloured & 1.6 & 1.0 & 7.5 & 2.5 & \\
\hline Indian & 0 & 3.8 & 25.5 & 3.1 & \\
\hline \multicolumn{6}{|l|}{ Exercise } \\
\hline $\begin{array}{l}\text { No regular exercise } \\
\text { (\%) }\end{array}$ & 96.9 & 96.0 & 94.3 & 93 & \multirow[t]{2}{*}{0.48} \\
\hline $\begin{array}{l}\text { At least once a } \\
\text { week }(\%)\end{array}$ & 3.1 & 4.0 & 5.7 & 7 & \\
\hline $\begin{array}{l}\text { Dieted in last } 6 \\
\text { months (\%) }\end{array}$ & 0 & 0 & 4.7 & $<1$ & 0.003 \\
\hline $\begin{array}{l}\text { Ever smoked } \\
\text { cigarettes (\%) }\end{array}$ & 11.0 & 10.3 & 10.4 & 16.1 & 0.17 \\
\hline Current smoker (\%) & 4.7 & 5.6 & 5.7 & 9.9 & 0.23 \\
\hline
\end{tabular}

Table II. Reproductive characteristics of subjects in the 40 - 49-year age group by contraceptive method

\begin{tabular}{|c|c|c|c|c|c|}
\hline Characteristics & $\begin{array}{l}\text { DMPA } \\
(N=127)\end{array}$ & $\begin{array}{l}\text { NET-EN } \\
(N=102)\end{array}$ & $\begin{array}{l}\mathrm{COC} \\
(N=106)\end{array}$ & $\begin{array}{l}\text { Nonuser } \\
(N=161)\end{array}$ & $p$ value \\
\hline Mean parity (SD) & $3.6+1.6$ & $2.9+1.5$ & $2.7+1.4$ & $3.3+1.7$ & 0.0001 \\
\hline Ever lactated (\%) & 88.2 & 91.3 & 87.7 & 83.2 & 0.34 \\
\hline Mean lactation (years, SD) & $4.6+3.9$ & $3.7+3.2$ & $3.0+3.0$ & $4.0+4.4$ & 0.02 \\
\hline Mean age at menarche(years, SD) & $15.2+1.7$ & $15.5+1.7$ & $14.8+1.7$ & $14.8+1.6$ & 0.014 \\
\hline Use of group method ${ }^{*}$ & & & & & $<0.0001$ \\
\hline Median use in last 5 yrs (months) & 53 & 45 & 52 & NA & \\
\hline Median lifetime use (months) & 84 & 49 & 89 & NA & \\
\hline Mean age at first use (years) & 36 & 37 & 36 & NA & \\
\hline
\end{tabular}

was associated with age, with an increase of $3.19 \mathrm{IU} / \mathrm{ml}(p \leq 0.0001)$ per year of age (40 - 49) for all groups combined. The FSH levels were significantly lower $(p \leq 0.0001)$ in the NET-EN users and COC users compared with the controls (Table III). There was, however, no difference between the DMPA users and the controls $(p=0.2)$. After adjusting the FSH level for age, the difference between the NET-EN 


\section{Table III. Mean FSH by users group}

\begin{tabular}{lll}
\hline Study group & $N$ & Mean FSH IU/ml (95\% CI) \\
\hline Non-users & 161 & $26.7(22.9-30.4)$ reference \\
DMPA & 127 & $23.1(18.9-27.3) ; p=0.2$ \\
NET-EN & 102 & $10.9(6.2-15.6) ; p \leq 0.0001$ \\
COC & 106 & $12.5(7.8-17.1) ; p \leq 0.0001$ \\
\hline
\end{tabular}

and COC users compared with the non-users persisted ( $p=0.003$ and 0.001 respectively) and there was no evidence of a difference between the DMPA users and non-users ( $p=0.64)$.

Table IV shows the proportion of women experiencing menopausal symptoms in each group. Although FSH levels were found to be lower in the COC and NET-EN groups, there was no evidence of a difference in the proportion of women falling into the perimenopausal FSH range compared with controls after adjusting for age (DMPA $p=0.51$; NET-EN $p=0.16$; COC $p=0.06$ ). The non-user group experienced a higher proportion of night sweats; however, after adjusting for age, we found no difference in reporting symptoms between hormonal contraceptive users and non-users. In total, $48.5 \%$ of women in the non-user group were classified as perimenopausal (reported at least one vasomotor symptom in the last 3 months and had an FSH in the perimenopausal/menopausal range). This was a higher proportion than in the other 3 groups (40.2\% DMPA, 31.4\% NET-EN, 30.1\% COCs); however, after adjusting for age, there was no evidence of a difference between the 4 groups in terms of menopausal status (DMPA $p=0.48$; NET-EN $p=0.93$; COC $p=0.29$ ) (Table IV).

Only $19.7 \%$ of women in the DMPA group and $33 \%$ of the NET-EN group reported a regular menstrual cycle (between 21 and 35 days), compared with $90 \%$ of the COC group and $93 \%$ of the non-users.

Although there was no age difference between the ethnic groups $(p=0.28)$. The Indian and coloured women had lower FSH values $(9.6 \mathrm{IU} / \mathrm{ml}$ and $16.6 \mathrm{IU} / \mathrm{ml}$ respectively) compared with black women $(20.5 \mathrm{IU} / \mathrm{ml})(p=0.03)$.

\section{Discussion}

After adjusting for age, we found no difference in reporting of vasomotor symptoms between the hormonal contraceptive users and non-users. DMPA has been used successfully to treat vasomotor symptoms ${ }^{2,3}$ and, in one study, ${ }^{4}$ vasomotor symptoms were relieved in 96\% of women treated with one dose of DMPA, the relief beginning within 4 - 7 days. Relief was sustained for between 8 and 20 weeks, with symptoms returning from around 2 months. In the study by Bullock et al., ${ }^{2} 89.5 \%$ of women experienced relief from vasomotor symptoms; however, in this study, women received a monthly

\section{Table IV. Association between menopausal symptoms and contraceptive method unadjusted and adjusted for age}

\begin{tabular}{|c|c|c|c|}
\hline $\begin{array}{l}\text { Menopausal } \\
\text { symptoms }\end{array}$ & $\%(N)$ & Unadjusted $\mathrm{OR}^{\star}(95 \% \mathrm{CI})$ & Age adjusted OR ( $95 \% \mathrm{CI})$ \\
\hline \multicolumn{4}{|l|}{ Night sweats } \\
\hline Non-users & $16.8(27)$ & 1 (reference) & 1 (reference) \\
\hline DMPA & $7.1(9)$ & $0.38(0.17-0.84)$ & $0.57(0.25-1.29)$ \\
\hline NET-EN & $3.8(4)$ & $0.20(0.07-0.58)$ & $0.36(0.12-1.12)$ \\
\hline $\mathrm{COC}$ & $8.5(9)$ & $0.46(0.21-1.02)$ & $0.70(0.30-1.60)$ \\
\hline \multicolumn{4}{|l|}{ Hot flushes } \\
\hline Non-users & $10.2(13)$ & 1 (reference) & 1 (reference) \\
\hline DMPA & $3.8(4)$ & $0.59(0.29-1.21)$ & $0.87(0.41-1.83)$ \\
\hline NET-EN & $8.5(9)$ & $0.21(0.07-0.61)$ & $0.36(0.12-1.10)$ \\
\hline $\mathrm{COC}$ & $16.2(26)$ & $0.48(0.22-1.07)$ & $0.70(0.31-1.61)$ \\
\hline \multicolumn{4}{|l|}{ Skin changes } \\
\hline Non-users & $18.9(24)$ & 1 (reference) & 1 (reference) \\
\hline DMPA & $19.0(20)$ & $0.81(0.45-1.44)$ & $1.04(0.57-1.89)$ \\
\hline NET-EN & $27.4(29)$ & $0.82(0.44-1.51)$ & $1.16(0.60-2.23)$ \\
\hline $\mathrm{COC}$ & $22.4(36)$ & $1.31(0.74-2.30)$ & $1.69(0.94-3.07)$ \\
\hline \multicolumn{4}{|l|}{ Dry vagina } \\
\hline Non-users & $2.4(3)$ & 1 (reference) & 1 (reference) \\
\hline DMPA & $1.9(2)$ & $0.21(0.06-0.77)$ & $0.27(0.76-0.99)$ \\
\hline NET-EN & $3.8(4)$ & $0.18(0.04-0.78)$ & $0.24(0.05-1.14)$ \\
\hline $\mathrm{COC}$ & $9.9(16)$ & $0.36(0.12-1.09)$ & $0.45(0.14-1.41)$ \\
\hline \multicolumn{4}{|c|}{$\mathrm{FSH}>20 \mathrm{mIU} / \mathrm{ml}(\%)$} \\
\hline Non-users & $37.7(39)$ & 1 (reference) & 1 (reference) \\
\hline DMPA & $31.0(17)$ & $0.74(0.45-1.21)$ & $1.20(0.70-2.07)$ \\
\hline NET-EN & $16.8(19)$ & $0.33(0.18-0.62)$ & $0.62(0.32-1.20$ \\
\hline $\mathrm{COC}$ & $18.5(60)$ & $0.37(0.21-0.67)$ & $0.54(0.29-1.02)$ \\
\hline \multicolumn{4}{|c|}{ Perimenopausal ${ }^{\star \star}(\%)$} \\
\hline Non-users & $48.5(78)$ & 1 (reference) & 1 (reference) \\
\hline DMPA & $40.2(51)$ & $0.71(0.45-1.14)$ & $1.21(0.72-2.04)$ \\
\hline NET-EN & $31.4(33)$ & $0.49(0.29-0.82)$ & $0.97(0.55-1.73)$ \\
\hline $\mathrm{COC}$ & $30.5(32)$ & $0.47(0.28-0.78)$ & $0.74(0.42-1.30)$ \\
\hline
\end{tabular}


injection of DMPA $(150 \mathrm{mg}$ ) which is more frequent than the dose used for contraceptive purposes. In our study, we asked about any episode of vasomotor symptoms in the last 3 months; however, the study was not set up to collect frequency within that time period. It might have been that women in our study using DMPA were relieved of symptoms in the first 2 months of the injection cycle but symptoms returned towards the end of the 3-month injection cycle. This requires further investigation. There are no data on NET-EN and suppression of vasomotor symptoms, which may be because the method is not as widely used as DMPA. However, this study shows slightly lower reporting of night sweats in NET-EN compared with DMPA users, which may suggest that it also has the potential to relieve some vasomotor symptoms in women.

Our study found evidence that, although mean FSH was lower in NET-EN and COC users compared with DMPA and non-users after adjusting for age, there was no evidence of a difference in the proportion of each user group classified in the perimenopausal FSH range. COCs are known to suppress FSH levels to a greater extent than DMPA; ${ }^{12}$ however, limited information exists on NET-EN suppression of FSH in this age group. Ethnic differences in age at natural menopause could also be another possible explanation for the lower FSH levels in the COC group. ${ }^{13}$ This group comprised the highest proportion of Indian women (25.5\%), and Indian women had significantly lower FSH than the black women of the same age, which adds to existing evidence that there are differences associated with ethnicity and age at natural menopause. ${ }^{13}$

In South Africa, alternatives to hormonal contraception such as sterilisation and the IUD are not readily accessible in the public health sector, and women will often continue to use hormonal injectables into their late 40 s and beyond.?

Our study suggests that some women use hormonal contraception when they are in the menopausal transition. The variability of FSH levels during the perimenopause has called into question the reliability of using the FSH measure to diagnose or predict menopause. ${ }^{6}$ However, in hormonal injectable users, it may be one of the only means of assessing approaching menopause without discontinuing the method. This finding has important implications for guiding family planning providers, as South Africa has no guidelines on how to manage older injectable contraceptive users. In the public health sector, women are normally advised to remain on their methods until at least 50 years or until they report menopausal symptoms. In some cases, a single FSH measurement will be taken, normally after a method has been discontinued. Women could have FSH levels measured without discontinuing the method provided that the test is taken at the end of the injection cycle for both NET-EN and DMPA. A benefit to continuing use of injectables may be some relief of vasomotor symptoms associated with menopause.

Our study has several limitations. Cross-sectional in design, the data include only one FSH measurement where the timing of measurement was not always at the end of the injection cycle or 7th day of the pill-free interval. Women were asked whether they had experienced any symptoms of menopause in the last 3 months, but the study was not set up to ask about the frequency of these symptoms over the 3-month period. However, the study indicates that menopausal symptoms and high FSH levels can be detected in some women, and this warrants further investigation with a larger sample size.

\section{References}

1. World Health Organisation Special Programme of Research, Development and Research Training in Human Reproduction. Task Force on Long-acting Systemic Agents for the Regulation of Fertility. Multinational comparative clinical evaluation of two long-acting injectable contraceptive steroids: Norethisterone enanthate given in two dosage regimens and depot medroxyprogesterone acetate: Final Norethisterone enanthate given in

report. Contraception 1983;23:1-20.
2. Bullock JL, Massey FM, Gambrell RD Ir. Use of medroxyprogesterone acetate to prevent menopausal Bullock JL, Massey FM, Gambrell RD Jr. Use of
symptoms. Obstet Gynecol 1975;46(2):165-168.

3. Morrison JC, Martin DC, Blair RA, et al. The use of medroxyprogesterone acetate for the relief of climacteric symptoms. Am J Obstet Gynecol;1980;138(1):99-104.

4. Franchimont P, Cession G, Ayalon D, Musters A, Legros JJ. Suppressive action of norethisterone enanthate and depo medroxyprogesterone acetate on gonadotropin levels. Obstet Gynecol 1970;36:93100.

5. Guilleband J. Contraception: Your Questions Answered. Edinburgh: Churchill Livingstone;1993:280. 6. Nelson AL, Stewart FH. Menopause. In: Hatcher RA, Trussel J, Nelson AL, et al., eds. Contraceptive Technology, 18th ed. New York: Ardent Media, 2004:78.

Department of Health, Medical Research Council, OrcMacro. South African Demographic and Health Survey 2003. Pretoria: Department of Health, 2007.

8. Perez-Palacois G, Chavez B, Escobar N, et al. Mechanism of action of contraceptive synthetic progestins. J Steriod Biochem 1981;15:125-130

Beksinska ME, Smit IA, Kleinschmidt I, Rees HV, Farley TMM, Guidozzi F. Detection of raised FSH levels among older women using depot-medroxyprogesterone acetate and norethisterone enanthate. levels among older women using

10. Fotherby K, Saxena B.N, Shrimanker K, et al. A preliminary pharmacokinetic and pharmacodynamic evaluation of depot medroxyprogesterone acetate and norethisterone oeanthate. Fertil Steril 1980;34:131-138

11. Beksinska M, Smit J, Kleinschmidt I, Farley T, Mbatha F. Bone mineral density in women aged 4049 years using depot-medroxyprogesterone acetate, norethisterone enanthate or combined ora contraceptives for contraception. Contraception 2005;71:170-175.

12. Castracane VD, Gimpel T, Goldzieher JW. When is it safe to switch from oral contraceptives to hormonal replacement therapy? Contraception 1995:52:371-376.

13. Gold EB, Colvin A, Avis N, et al. Longitudinal analysis of the association between vasomotor symptoms and race/ethnicity across the menopausal transition: Study of women's health across the nation. APJH 2006:96:1226-1235.

Accepted 30 June 2010. 